\title{
Peroxisome Proliferator-activated Receptors as Potential Targets for Carcinogenic Activity of Polychlorinated Biphenyls: A Computational Perspective
}

\author{
ISHFAQ AHMAD SHEIKH ${ }^{1}$, ARWA ABU KHWEEK ${ }^{2}$ and MOHD AMIN BEG ${ }^{1}$ \\ ${ }^{1}$ King Fahd Medical Research Center, King Abdulaziz University, Jeddah, Kingdom of Saudi Arabia; \\ ${ }^{2}$ Department of Biology and Biochemistry, Birzeit University, Birzeit, West Bank, Palestine
}

\begin{abstract}
Background: Polychlorinated biphenyls (PCBS) are ubiquitous environment-contaminating synthetic chemicals that have been associated with increased risk of hepatic cancer, melanoma, non-Hodgkin lymphoma and cancer of many other body organs. Structural binding analyses of $P C B 77$ and $P C B 118$ with peroxisome proliferator-activated receptors (PPAR $\alpha, P P A R \beta / \delta$ and $P P A R \gamma)$ was performed to predict the association of PCBs with potential disruption of PPAR signaling pathways. Materials and Methods: The crystal structures of human $P P A R \alpha, P P A R \beta / \delta$ and PPAR $\gamma$ were obtained from the Protein Data Bank. Structures of $P C B 77$ and $P C B 118$ were obtained from PubChem database. Docking was performed using glide (Schrodinger) induced fit docking (IFD) module. Results: The $P C B 77$ and PCB 118 interacted with PPAR $\alpha, P P A R \beta / \delta$ and $P P A R \gamma$ showing an overlapping of 40-58\% interacting amino acid residues with synthetic co-complex agonists of the three PPARs. The binding affinity was higher for PCB 118 than for $P C B 77$ during docking interactions with each of the three PPARs. Conclusion: The consistent commonality of interacting residues for $P C B 77$ and $P C B 118$ with cocomplex synthetic agonists of the PPARs together with good binding affinity suggested that the PPAR signaling pathway is a potential target for toxicologic activity of PCBs.
\end{abstract}

Environmental contamination, resulting as a consequence of global chemical industry, has become a major concern for the human and animal health throughout the world. Among the hundreds of thousands of the man-made chemicals manufactured for commercial purpose in the world, about a

Correspondence to: Ishfaq Ahmad Sheikh, King Fahd Medical Research Center, King Abdulaziz University, P.O. Box 80216, Jeddah-21589, Kingdom of Saudi Arabia. Tel: +966 6401000 (ext. 25415), Fax: +966 6952076, e-mail: iasheikh@kau.edu.sa

Key Words: Docking, PPAR $\alpha$, PPAR $\beta / \delta$, PPAR $\gamma$, PCB 77, PCB 118. thousand chemicals are suspected to predispose the human population to the abnormal reproductive function, increased incidence of cancer, neurodevelopmental problems and impaired immune function (1-3).

Polychlorinated biphenyls (PCBs) are a class of hazardous man-made aromatic chemicals that are ubiquitous environmental pollutants due to their persistence in the environment $(4,5)$. PCBs have a biphenyl structure with two linked benzene rings where the hydrogen atom is substituted by chlorine $(6,7)$. The degree and position of chlorination can result in 209 different molecules also called as congeners and affects the physical nature of PCBs, which can be either oily liquid or solid. Commercial PCB products generally contain a mixture of different PCB congeners (8). On account of the low water solubility, low flammability with low electrical conductivity and lipophilic properties, PCBs were widely used since 1930s as coolants and lubricants in capacitors, transformers, cooling liquids, hydraulic fluid, pesticides and copy paper (9). The estimated total global production of PCBs until 1977 was about 1.5 billion pounds $(8,10)$. The PCBs were banned in the USA in 1977 but about $2 / 3$ rds of PCB products, such as insulation fluids, plastics, adhesives, paper, inks, etc., manufactured before the ban, are still used today and are a source of exposure together with landfills and waste dumps that contain the disposed PCB products (11). The United States Environmental Protection Agency has identified PCBs in 500 of the 1,598 most serious hazardous waste sites listed in its national priority list and these sites were targeted for longterm federal cleanup activities (8).

Human exposure of $\mathrm{PCB}$ results from ingesting $\mathrm{PCB}$ contaminated food, water or polluted air and can also occur during repair and maintenance of PCB transformers or due to accidents, fires and spills involving PCB transformers and older computers and instruments (12). PCBs are bioaccumulative and may remain stored in the body organs for years. A recent study estimated the halflives of some of the PCB congeners in the ranges of 21 to 
133 years (13). Based on carcinogenicity evidence in humans and experimental animals, PCBs were classified as probable carcinogens (group 1) by the International Agency for Research on Cancer (IARC) in 2013 (14). The PCBs-induced carcinogenesis is not due to genotoxicity but is a result of several non-genotoxic mechanisms, such as cancer promotion, peroxisome proliferation, hormone imbalance and cytotoxicity resulting in progressive cell division $(15,16)$.

Epidemiological and animal experimental studies have consistently shown association of PCBs with carcinogenicity $(8,17)$. An increase in the incidence of liver, gallbladder and biliary tract cancer was found on retrospective analyses in workers at two capacitor manufacturing plants in the United States (18). Several other studies (19-22) reported that exposure to insulating fluids containing PCBs was associated with an increase in incidence of malignant melanoma and brain cancer. Further, an increased risk for cancers of liver, stomach, intestines and thyroid was found in association of PCBs during mortality studies in workers at a capacitor manufacturing plant from 1944-1977 (23). Even without known occupational exposure, higher risk of non-Hodgkin lymphoma was found in patients with increased PCB levels in the adipose tissue and serum (24-26). In a recent study on a large cohort of 24,865 workers (27), PCB exposure was related with total cancer and intestinal cancer mortality of females and myeloma in males. A number of experimental studies in laboratory animals have also shown that all PCB mixtures caused gastrointestinal tract tumors, hepatocarcinomas, leukemia, lymphomas and pituitary tumors $(8,28,29)$. There is considerable variability in toxicity of PCB congeners and, in general, coplanar PCBs are considered more toxic PCBs. The congeners 3,3',4,4'tetrachlorobiphenyl (PCB 77) and 2,3',4,4',5pentachlorobiphenyl (PCB 118) are two examples of coplanar PCBs. PCB 77 is one of the three most toxic PCBs known. PCB 118 is one of the most frequently and consistently detected congener in the United States biomonitoring studies (30) and one of the two PCBs that share a toxicity equivalent of $25 \%$ for United States population (31).

Environmental contaminants are commonly thought to induce the adverse effects in human systems by disrupting nuclear receptor signaling pathways (1). One such signaling pathway involves peroxisome proliferator-activated receptors (PPARs) that belong to the ligand-activated nuclear receptor superfamilies and include the steroid, thyroid and retinoid hormone receptors $(32,33)$. There are three different PPAR isoforms, PPAR- $\alpha$, PPAR- $\beta / \delta$ and PPAR- $\gamma$, with significant homology playing specific functional roles in the human body $(34,35)$. The PPAR $\alpha$ plays a major role in regulating fatty acid homeostasis $(36$, 37 ) and regulates the peroxisomal and mitochondrial $\beta$ - oxidation pathways, which are involved in the pathogenesis of various liver complications, such as hepatocarcinogenesis in a rodent model and drug-induced liver injury (38). The $\mathrm{PPAR} \beta / \delta$ is associated with an increase in lipid catabolism in adipose tissue, skeletal muscle and the heart, as well as induction of cell proliferation and differentiation $(39,40)$. The PPAR $\gamma$ plays a major role in glucose metabolism and in differentiation of adipocytes and also functions as a transcriptional regulator in pathways that are required for these metabolic processes $(37,41,42)$. Following binding with their corresponding ligands, PPARs undergo conformational changes that displace the co-repressors and recruit certain co-activator complexes that regulate several normal physiological processes and, thus, disruption of PPARs pathways contributes to disease progression in obesity, diabetes and cancers $(34,43)$.

In the present study, the potential molecular mechanisms for PCBs-mediated cancer formation were elucidated by investigating the structural binding characteristics of PCBs with PPARs using in silico predictive approaches. Docking studies involved the study of binding mechanisms, distinctive binding pattern and interacting residues of PPAR $\alpha, \operatorname{PPAR} \beta / \delta$ and PPAR $\gamma$ with PCB 77 and PCB 118. It was expected that the approach via computational systems would help in predicting potential carcinogenic risks of the PCBs, which are ubiquitously contaminating the environment.

\section{Materials and Methods}

Data retrieval. The molecular structures of PCB 77 and PCB 118 were obtained from PubChem compound database (https:// pubchem.ncbi.nlm.nih.gov/). The two dimensional structures of the PCB ligands are illustrated in Figure 1 and their abbreviations and PubChem compound identities (CIDs) are presented in Table I. Schrodinger 2015 suite with Maestro 10.3 (a graphical user interface) software (Schrodinger, LLC, New York, NY, USA) was used for docking studies of PCB 77 and PCB 118 with PPAR $\alpha$, $\operatorname{PPAR} \beta / \delta$ and PPAR $\gamma(44)$.

Protein and ligand preparation. The Protein Data Bank ((PDB) http://www.rcsb.org/) was scanned for the crystal structure of human PPAR $\alpha$ (PDB code: 3VI8), PPAR $\beta / \delta$ (PDB code: 3TKM) and PPAR $\gamma$ (PDB code: 3 NOA). The crystal structures of the three PPARs were co-complexes with synthetic agonist ligands CHEMBL1956149, GW0742 and 5BC, respectively (see Table I for full IUPAC names), and the crystal structure of PPAR $\alpha$ is shown in Figure 1 as an example. The details for the preparation of the receptors and the ligands for docking analysis using Schrodinger Glide (Schrodinger suite 2015-3; Schrodinger, LLC) were described previously (44).

Induced fit docking. Schrodinger's induced fit docking (IFD) module was used for docking analyses of the PCB 77 and PCB 118 with PPAR $\alpha, \operatorname{PPAR} \beta / \delta$ and PPAR $\gamma$ as already described (44, 45). A softened-potential docking is performed in the first IFD 


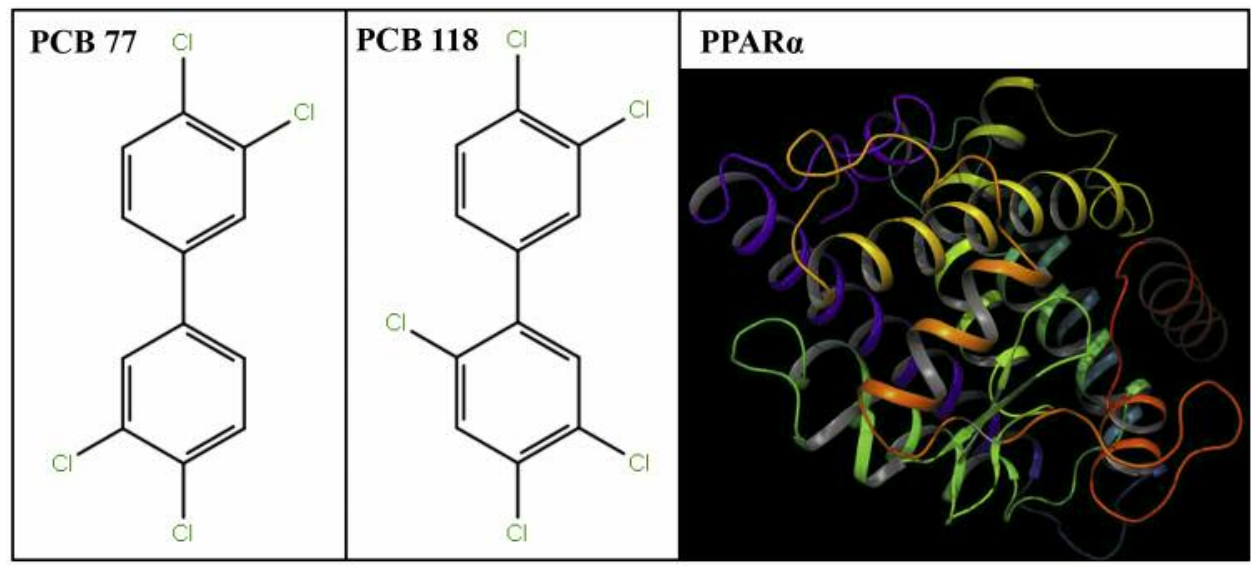

Figure 1. Two-dimensional representation of the two PCBs, 3,3',4,4'-tetrachlorobiphenyl (PCB 77) and 2,3',4,4',5-pentachlorobiphenyl (PCB 118), and ribbon form representation of crystal structure of peroxisome proliferator-activated receptor $\alpha(P P A R \alpha)$.

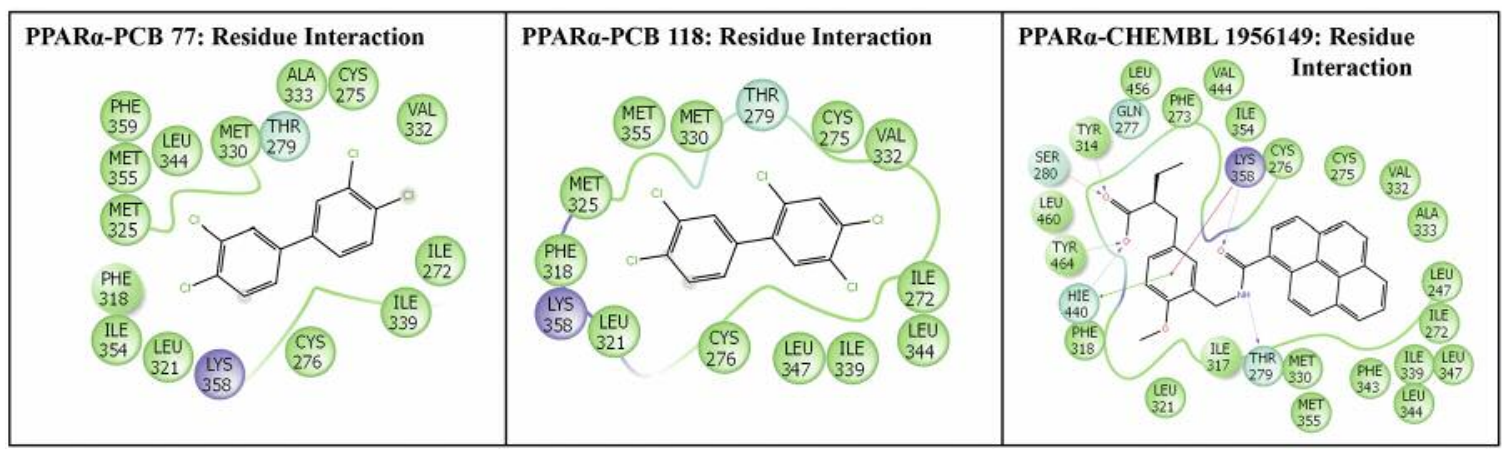

Figure 2. Amino-acid residue interaction display in the binding pocket of peroxisome proliferator-activated receptor $\alpha(P P A R \alpha)$ for interactions with 3,3',4,4'-tetrachlorobiphenyl (PCB 77), 2,3',4,4',5-pentachlorobiphenyl (PCB 118) and PPARa co-complex synthetic agonist, CHEMBL19561.

Table I. Nomenclature, commonly used abbreviations and PubChem IDs of the two PCBs and the three co-complex bound ligands of peroxisome proliferator-activated receptors (PPAR $\alpha, P P A R \beta / \delta$ and PPAR $\gamma$ ).

\begin{tabular}{|c|c|c|c|}
\hline S.No. & Name & Abbreviation & PubChem ID \\
\hline 1 & 3,3',4,4'-Tetrachlorobiphenyl & РCB 77 & 36187 \\
\hline 2 & 2,3',4,4',5-Pentachlorobiphenyl & PCB 118 & 35823 \\
\hline 3 & $\begin{array}{c}\text { (2S)-2-[[4-methoxy-3-[(pyrene-1-carbonylamino)methyl]phenyl]methyl]butanoic acid } \\
\text { (co-complex ligand for PPAR } \alpha)\end{array}$ & CHEMBL1956149 & 25112371 \\
\hline 4 & $\begin{array}{c}\text { 2-[4-[[2-[3-fluoro-4-(trifluoromethyl)phenyl]-4-methyl-1,3-thiazol-5-yl]methylsulfanyl]- } \\
\text { 2-methylphenoxy]acetic acid (co-complex ligand for PPAR } \beta / \delta \text { ) } \\
9934458\end{array}$ & GW0742 & \\
\hline 5 & $\begin{array}{l}\text { 2-[5-[3-[4-(4-phenylbenzoyl)-2-propylphenoxy]propoxy]indol-1-yl]acetic acid } \\
\text { (co-complex ligand for PPAR } \gamma \text { ) }\end{array}$ & $5 \mathrm{BC}$ & 49850232 \\
\hline
\end{tabular}

stage where docking of the ligand occurs into an ensemble of the binding protein conformations. Subsequently, complex minimization for highest ranked pose is performed where ligand, as well as the binding sites, are free to move. Prime module of
Schrodinger 2015 with molecular mechanics generalized Bornsurface area (MMGB-SA) function was used for the ligand binding affinity calculations against the $\operatorname{PPAR} \alpha, \operatorname{PPAR} \beta / \delta$ and PPAR $\gamma$ crystal complexes. 


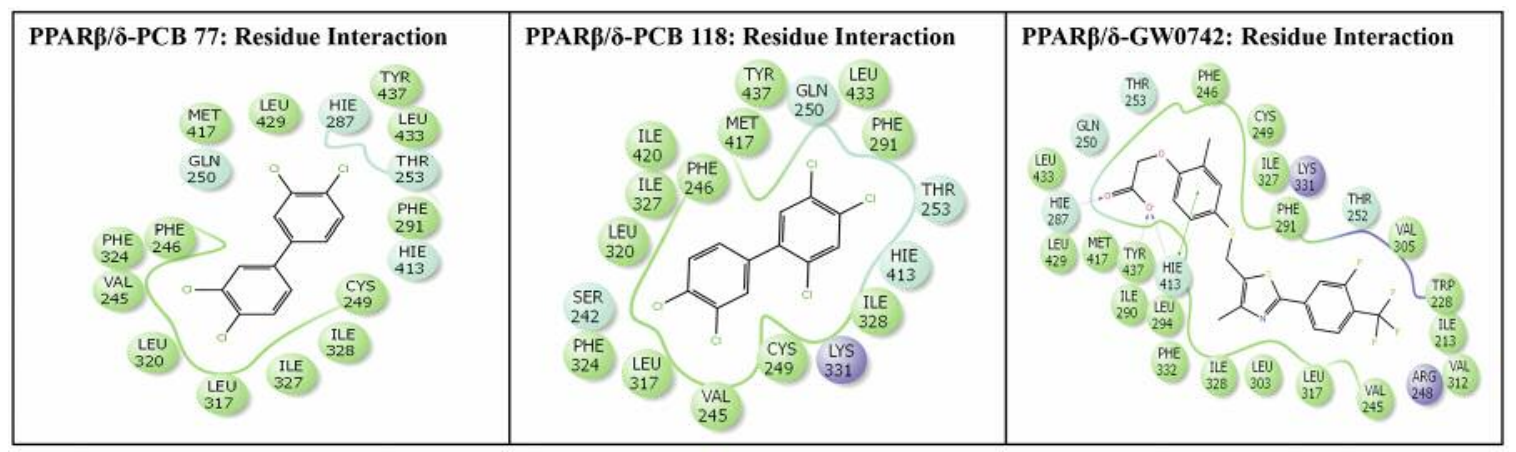

Figure 3. Amino-acid residue interaction display in the binding pocket of peroxisome proliferator-activated receptor $\beta / \delta(P P A R \beta / \delta)$ for interactions with 3,3',4,4'-tetrachlorobiphenyl (PCB 77), 2,3',4,4',5-pentachlorobiphenyl (PCB 118) and PPAR $\beta / \delta$ co-complex synthetic agonist, GW0742.

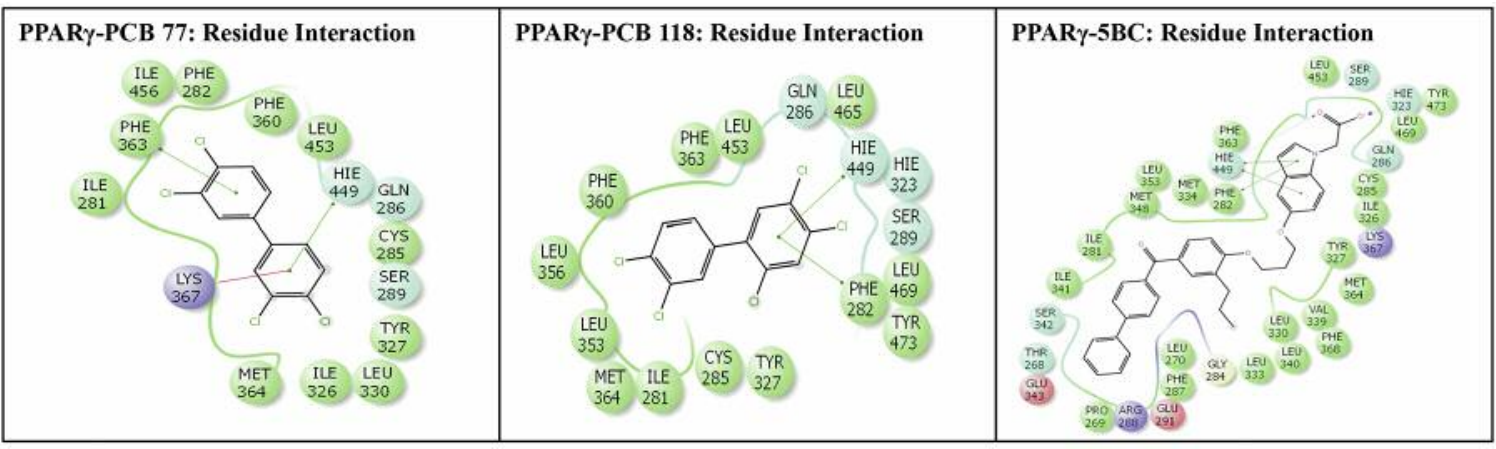

Figure 4. Amino-acid residue interaction display in the binding pocket of peroxisome proliferator-activated receptor $\gamma(P P A R \gamma)$ for interactions with 3,3',4,4'-tetrachlorobiphenyl (PCB 77), 2,3',4,4',5-pentachlorobiphenyl (PCB 118) and PPAR $\gamma$ co-complex synthetic agonist, 5BC.

\section{Results}

Docking simulation of PCB 77 and PCB 118 was successfully executed by IFD against PPAR $\alpha, \operatorname{PPAR} \beta / \delta$ and $\operatorname{PPAR} \gamma$ resulting in multiple docking poses for each ligandreceptor interaction. The best pose for each of the ligands with each of the three receptors was identified and used for computational analyses of ligand-receptor structural binding characteristics. Similarly, the best docking pose for bound co-complex ligands of each of the receptors were utilized for analyses.

Molecular docking studies of PCB 77 and PCB 118 with $P P A R \alpha$. The docking complexes of the two PCB ligands, PCB 77 and PCB 118, and co-complex ligand, CHEMBL 1956149, with PPAR $\alpha$ showed interactions with 16, 14 and 27 amino-acid residues, respectively (Figure 2; Table II). Of these interacting residues, 14 residues for PCB 77 and 13 residues for $\mathrm{PCB} 118$ overlapped with interacting residues for co-complex bound ligand CHEMBL 1956149 (commonality of $52 \%$ and $48 \%$; Table II). Twelve residues of PPAR $\alpha$ (Ile272, Cys-275, Cys-276, Thr-279, Phe-318, Leu-321, Met-330, Val-332, Ile-339, Leu-344, Met-355 and Lys-358) were common among both the PCBs and the bound ligand. Further, PPAR $\alpha$ interacting residues Ala-333 and Ile-354 were also common between PCB 77 and bound ligand but not for PCB 118. Conversely, residue Leu-347 was common for PCB 118 and the bound ligand but not for PCB 77. The bound ligand, CHEMBL 1956149, formed 6 hydrogen bonding interactions with interacting residues Thr-279, Ser-280, Tyr-314, Lys-358 and Tyr-464 of PPAR $\alpha$. Additionally, 1 pi-pi interaction displayed by His-440 and 1 cation-pi interaction is also observed between Lys-358 and CHEMBL. However, no hydrogen bonding interactions were present for both PCB docking complexes. The dock score, glide score and binding affinity were highest in the bound co-complex ligand followed by PCB 118 and PCB 77 (Table II).

Molecular docking studies of PCB 77 and PCB 118 with $P P A R \beta / \delta$. The docking displays of the two PCB ligands, 
Table II. Number of interacting residues, number and percentage of residues common with co-complex bound ligands, induced fit docking (IFD) score, dock score, glide score and binding affinity values (molecular mechanics generalized Born-surface area (MMGB-SA) values) of 3,3',4,4'tetrachlorobiphenyl (PCB 77) and 2,3',4,4',5-pentachlorobiphenyl (PCB 118) after induced fit docking (IFD) with human peroxisome proliferatoractivated receptors (PPAR $\alpha, P P A R \beta / \delta$ and PPAR $\gamma$ ).

\begin{tabular}{|c|c|c|c|c|c|c|c|}
\hline Target & Ligand & $\begin{array}{l}\text { Number of interacting } \\
\text { residues }\end{array}$ & $\begin{array}{c}\text { Number of } \\
\text { interacting residues } \\
\text { common with native }(\%)\end{array}$ & IFD score & $\begin{array}{l}\text { Docking score } \\
(\mathrm{Kcal} / \mathrm{mol})\end{array}$ & $\begin{array}{l}\text { Glide score } \\
(\mathrm{Kcal} / \mathrm{mol})\end{array}$ & $\begin{array}{r}\text { MMGB-SA } \\
(\mathrm{Kcal} / \mathrm{mol})\end{array}$ \\
\hline \multirow[t]{3}{*}{ PPAR $\alpha$} & РCB 77 & 16 & $14(52 \%)$ & -594.81 & -7.97 & -7.97 & -87.09 \\
\hline & PCB 118 & 14 & $13(48 \%)$ & -595.63 & -8.43 & -8.43 & -104.07 \\
\hline & Native & 27 & $27(100 \%)$ & -601.86 & -14.21 & -14.21 & -130.11 \\
\hline \multirow[t]{3}{*}{$\mathrm{PPAR} \beta / \delta$} & РCB 77 & 17 & $15(58 \%)$ & -602.77 & -7.81 & -7.81 & -84.61 \\
\hline & PCB 118 & 18 & $14(54 \%)$ & -603.79 & -8.43 & -8.43 & -96.94 \\
\hline & Native & 26 & $26(100 \%)$ & -610.49 & -12.93 & -12.93 & -115.89 \\
\hline \multirow[t]{3}{*}{$\operatorname{PPAR} \gamma$} & РCB 77 & 15 & $13(39 \%)$ & -601.87 & -8.36 & -8.36 & -92.85 \\
\hline & PCB 118 & 17 & $14(42 \%)$ & -602.91 & -8.78 & -8.78 & -107.74 \\
\hline & Native & 33 & $33(100 \%)$ & -612.12 & -13.98 & -13.98 & -134.55 \\
\hline
\end{tabular}

PCB 77 and PCB 118, and co-complex ligand, GW0742, with $\mathrm{PPAR} \beta / \delta$ showed interactions with 17,18 and 26 amino-acid residues, respectively (Figure 3; Table II). Of these interacting residues, 15 residues for PCB 77 and 14 residues for $\mathrm{PCB} 118$ overlapped with interacting residues for co-complex bound ligand GW0742 (commonality of 58\% and 54\%; Table II). Thirteen residues of PPAR $\beta / \delta$ (Val-245, Phe-246, Cys-249, Gln-250, Thr-253, Phe-291, Leu-317, Ile327, Ile-328, His-413, Met-417, Leu-433 and Tyr-437) were common among both the PCBs and the bound ligand. Further, PPAR $\beta / \delta$ interacting residues His-287 and Leu-429 were also common between PCB 77 and bound ligand but not for PCB 118. Conversely, residue Lys-331 was common for PCB 118 and the bound ligand but not for PCB 77. In addition, residues Leu-320 and Phe-324 were common for both PCBs but not for the bound ligand. The bound ligand, GW0742, formed 3 hydrogen bonding interactions with interacting residues His-287, His-413 and Tyr-437 of $\operatorname{PPAR} \beta / \delta$. In addition, 1 pi-pi interaction is also observed between GW0742 and His-413 but no hydrogen bonding interactions were present for both PCB docking complexes (Figure 3). The dock score, glide score and binding affinity were highest for the bound co-complex ligand, GW0742, followed by PCB 118 and PCB 77 (Table II).

Molecular docking studies of $P C B 77$ and $P C B 118$ with $P P A R \gamma$. The docking displays of the two PCB ligands, PCB 77 and PCB 118, and co-complex ligand, 5BC, with PPAR $\gamma$ showed interactions with 15,17 and 33 amino-acid residues, respectively (Figure 4; Table II). Of these interacting residues, 13 residues for PCB 77 and 14 residues for PCB 118 overlapped with interacting residues for co-complex bound ligand 5BC (commonality of $39 \%$ and $42 \%$; Table II). Ten residues of PPAR $\gamma$ (Ile-281, Phe-282, Cys-285, Gln-286,
Ser-289, Tyr-327, Phe-363, Met-364, His-449 and Leu-453) were common among both the PCBs and the bound ligand. Further, PPAR $\gamma$ interacting residues Ile-326, Leu-330 and Lys-367 were also common between PCB 77 and bound ligand but not for PCB 118. Conversely, residues, His-323, Leu-353, Leu-469 and Tyr-473 were common for PCB 118 and the bound ligand but not for PCB 77. In addition, PCB 77 formed 2 pi-pi interactions with residues Phe-363, His449 and 1 cation-pi interaction with Lys-367 of PPAR $\gamma$. PCB 118 formed 2 pi-pi interactions with residues Phe-282 and His-449 of PPAR $\gamma$. The bound ligand, 5BC, formed 2 hydrogen bonding interactions with interacting residues His323 and His-449 and 3 pi-pi interactions with residues Phe282 and His-449 of PPAR $\gamma$. However, no hydrogen bonding interactions were present for PCB 118 and PCB 77 docking complex (Figure 4). The dock score, glide score and binding affinity were highest for the bound co-complex ligand, 5BC, followed by PCB 118 and PCB 77 (Table II).

\section{Discussion}

The present computational study was undertaken to clarify the molecular interactions of PCB 77 and PCB 118 with $\operatorname{PPAR} \alpha, \operatorname{PPAR} \beta / \delta$ and PPAR $\gamma$ in order to predict the association of known carcinogenic activity of PCBs with potential disruption of PPAR signaling pathways. PCB 77 and PCB 118 are two dioxin-like congeners of coplanar PCBs present in the mixtures of commercially available synthetic PCBs that are used as coolants and lubricants in capacitors, transformers and other electrical equipment because of their good insulating and non-inflammable properties (9). Based on epidemiological evidence in humans and experimental results in animals, IARC classified PCBs as probable carcinogens (group 1) in 2013 (14). Despite the 
ban on PCBs since 1977 and extensive and strict regulations, old PCB-containing products continue to be used commercially and, together with earlier persisting environmental contamination, remain a focus of constant attention and cause for concern. Recent biomonitoring data show that PCBs continue to be detected in the body fluids of the general population in the United States (30).

Structural binding analyses of the docking complexes of PCB 77 and PCB 118 with each of the PPAR $\alpha, \operatorname{PPAR} \beta / \delta$ and PPAR $\gamma$ revealed that a number of important amino acid residues of each receptor were involved in interactions with both PCBs. Good dock scores and high binding affinity indicated that the docking complexes were in their favorable conformation resulting in good quality docking. The interacting amino acid residues exerted hydrophobic and hydrophilic interactions contributing to the stability of the docking complex. During docking of both the PCBs, PCB 77 and PCB 118, with each of the three PPARs there was an overlapping of $39-58 \%$ amino acid residues with interacting residues of highly specific synthetic co-complex ligands for each receptor indicating similarity in the interaction pattern of the PCBs with native co-complex ligand at the common ligand binding domain of each receptor. This consistent commonality of interacting residues between the two PCBs and the co-complex ligand for each PPAR suggested that the PCBs could potentially interfere in the normal receptor function of the PPARs and, thus, cause signaling dysfunction. The PCB 118 interacted with a higher binding affinity with the PPARs than PCB 77 indicating tighter interactions. Also, among the PPAR $\alpha, \operatorname{PPAR} \beta / \delta$ and PPAR $\gamma$, docking simulation was stronger for both PCBs with PPAR $\alpha$, PPAR $\gamma$ than with PPAR $\beta / \delta$ on the basis of dock score, glide score and binding affinity. Thus, on a preliminary basis, PCB 118 seemed to be a more potent PCB than the PCB 77 and the toxic effects of these congers could preferentially involve PPAR $\alpha$ and PPAR $\gamma$ pathways.

Apparently, in silico studies of PCBs, including PCB 77 and PCB 118 with PPARs, have not been reported. However, studies on docking simulations of several coplanar PCBs with other nuclear receptors, such as aryl hydrocarbon receptor, are available $(46,47)$. In vitro competitive binding studies of PCB 77 and PCB 118 with PPARs are also not apparently available. In a recent study (48), a luciferase reporter assay did not show activation of PPAR $\alpha$ and PPAR $\gamma$; however, the tests were performed with Aroclor 1260 , which is mixture of PCB congeners. At higher concentrations, Aroclor 1260 had an inhibitory effect on PPAR $\alpha$ but no effect on PPAR $\gamma$.

Several experimental studies have shown the toxic effects of PCBs, including PCB 77 and PCB 118, in animals and tissue culture $(17,29,49)$. Although not related to the binding of PCB 77 and PCB 118 to the PPARS, some of these studies suggested, indirectly, an interaction of the two
PCBs with PPARs. PCB 77 increased cellular damage and stimulated the activation of oxidative stress-sensitive and proinflammatory transcription factors (50). The inflammatory processes, thus, activated are critical for atherosclerogenic pathology in vascular endothelial cells. However, the PCB 77-induced inflammation was reduced by prior treatment of vascular endothelial cells with PPAR $\alpha$ agonists (51). PCB 77 also decreased the PPAR $\alpha$ and PPAR $\gamma$ mRNA and PPAR $\alpha$ and PPAR $\gamma$ protein expression in a dosedependent manner suggesting the relationship of PCB toxicity, in part, to inhibition of PPARs' function. Further, PCB 77-induced inhibition of PPARS also led to dysregulation of fatty acid uptake and metabolism, which may accelerate the adverse effects associated with inflammatory disease. Another study (52) also reported that coplanar PCB 126, which is structurally similar to PCB 77 , acted as an inverse agonist and reduced peroxisomal activity in rats. In contrast to these studies, expression of PPAR $\gamma$ was shown to be increased by PCB 77 in another study (53). PCB 118 was also shown to perturb the steroidogenic activity and protein expression in vitro in human adrenocortical carcinoma cell cultures suggesting adverse effects on normal cellular processes, e.g., protein synthesis, stress response and apoptosis (54). In another study (55), subchronic dietary exposure of PCB 77 and PCB 118 in rats induced moderate changes in the liver and thyroid and increased liver weight and hepatic ethoxyresorufin O-deethylase activity. In an exhaustive two-year study in rats (56), PCB 118 was shown to induce dose-dependent hepatic toxicity characterized by increased incidences of hepatocyte hypertrophy, inflammation, oval cell hyperplasia, pigmentation, eosinophilic and mixed cell foci, bile duct hyperplasia and neoplasms of liver, lung, pancreas and uterus.

In conclusion, the docking simulation study of PCB 77 and PCB 118 with PPAR $\alpha, \operatorname{PPAR} \beta / \delta$ and PPAR $\gamma$ indicated that both PCBS were involved in interactions with important amino acid residues of each of the three PPARs. There was about $39-58 \%$ commonality of the interacting residues between the two PCBs and the co-complex synthetic agonists of each of three PPARs. PCB 118 formed tighter interactions with the PPARs than PCB 77. The interactions of both PCBs with PPAR $\alpha$ and PPAR $\gamma$ were stronger than with PPAR $\beta / \delta$. This study suggested that, on a preliminary basis, PPAR $\alpha$, $\operatorname{PPAR} \beta / \delta$ and PPAR $\gamma$ are potential targets for the toxic carcinogenic effects of PCBs in the human body.

\section{Acknowledgements}

This project was funded by the National Plan for Science, Technology and Innovation (MAARIFAH) - King Abdulaziz City for Science and Technology - the Kingdom of Saudi Arabia - award number 12-BIO3082-03. The authors also acknowledge with thanks Science and Technology Unit, King Abdulaziz University for their technical support. 


\section{Conflicts of Interest}

The Authors have declared that no competing interests exist.

\section{References}

1 Diamanti-Kandarakis E, Bourguignon JP, Giudice LC, Hauser R, Prins GS, Soto AM Zoeller RT and Gore AC: Endocrinedisrupting chemicals: an Endocrine Society scientific statement. Endocr Rev 30: 293-342, 2009.

2 WHO-UNEP. State of the science of endocrine disrupting chemicals 2012. Bergman A, Heindel JJ, Jobling S, Kidd KA, Zoeller RT editors. WHO Press, Geneva, Switzerland, pp. 1-38, 2013.

3 Gore AC, Crews D, Doan LL, La Merrill M, Patisaul H and Zota A: Introduction to endocrine disrupting chemicals (EDCs) - a guide for public interest organizations and policy makers. Endocrine Society reports and white papers, pp. 1-76, 2014. (http://www.endocrine.org/advocacy-and-outreach/letters-andalerts/society-reports-and-white-papers).

4 Tanabe S: PCB problems in the future: foresight from current knowledge. Environ Pollut 50: 5-28, 1988.

5 Finklea J, Priester LE, Creason JP, Hauser T, Hinners T and Hammer DI: Polychlorinated biphenyl residues in human plasma expose a major urban pollution problem. Am J Public Health 62: 645-651, 1972.

6 Luzardo OP, Henriquez-Hernandez LA, Valeron PF, Lara PC, Almeida-Gonzalez M, Losada A, Zumbado M, Serra-Majem L, Alvarez-León EE and Boada LD: The relationship between dioxin-like polychlorobiphenyls and IGF-I serum levels in healthy adults: evidence from a cross-sectional study. PLoS One 7(5): e38213, 2012.

7 Kimbrough RD: Polychlorinated biphenyls (PCBs) and human health: an update. Crit Rev Toxicol 25: 133-163, 1995.

8 ATSDR 2000. Toxicological profile for polychlorinated biphenyls (PCBs). Public health statement. Agency for Toxic Substances and Disease Registry. Atlanta, GA: U.S. Department of Health and Human Services, Public Health Service. (http://www.atsdr.cdc.gov/toxprofiles/tp17.pdf).

9 Zani C, Toninelli G, Filisetti B and Donato F: Polychlorinated biphenyls and cancer: an epidemiological assessment. J Environ Sci Health C Environ Carcinog Ecotoxicol Rev 31: 99-144, 2013.

10 Breivik K, Sweetman A, Pacyna JM and Jones KC: Towards a global historical emission inventory for selected PCB congenersa mass balance approach. 1. Global production and consumption. Sci Total Environ 290: 181-198, 2002.

11 Dyke PH, Foan C and Fiedler H. PCB and PAH releases from power stations and waste incineration processes in the UK. Chemosphere 50: 469-480, 2003.

12 Annamalai $\mathrm{J}$ and Namasivayam V: Endocrine disrupting chemicals in the atmosphere: Their effects on humans and wildlife. Environ Int 76: 78-97, 2015.

13 Hopf NB, Ruder AM, Waters MA and Succop P: Concentration dependent half-lives of polychlorinated biphenyl in sera from an occupational cohort. Chemosphere 91(2): 172-178, 2013.

14 Lauby-Secretan B, Loomis D, Grosse Y, El Ghissassi F, Bouvard V, Benbrahim-Tallaa L, Guha N, Baan R, Mattock H and Straif $\mathrm{K}$ : Carcinogenicity of polychlorinated biphenyls and polybrominated biphenyls. Lancet Oncol 14: 287-288, 2013.
15 Hodgson E and Levi PE: Pesticides: an important but underused model for the environmental health sciences. Environ Health Perspect 104(Suppl 1): 97-106, 1996.

16 Safe S: Polychlorinated biphenyls (PCBs): mutagenicity and carcinogenicity. Mutat Res 220: 31-47, 1989.

17 ATSDR 2014: Polychlorinated biphenyls (PCBs) toxicity: what are adverse health effects of PCB exposure? Case studies in environmental medicine. Agency for Toxic Substances and Disease Registry. Atlanta, GA: U.S. Department of Health and Human Services, Public Health Service. (http:// www.atsdr.cdc.gov/ csem/pcb/docs/pcb.pdf).

18 Brown DP: Mortality of workers exposed to polychlorinated biphenyls - an update. Arch Environ Health 42(6): 333-339, 1987.

19 Bahn AK, Rosenwaike I, Hermann N, Grover P, Stellman J and O'Leary K. Letter: Melanoma after exposure to PCB's. New England Journal of Medicine 295(8): 450, 1976.

20 Sinks T, Steele G, Smith AB, Watkins K and Shults RA: Mortality among workers exposed to polychlorinated biphenyls. Am J Epidemiol 136(4): 389-398, 1992.

21 Loomis D, Browning SR, Schenck AP, Gregory E and Savitz DA: Cancer mortality among electric utility workers exposed to polychlorinated biphenyls. Occup Environ Med 54(10): 720-728, 1997.

22 Ruder AM, Hein MJ, Nilsen N, Waters MA, Laber P, DavisKing K, Prince MM and Whelan E. Mortality among workers exposed to polychlorinated biphenyls (PCBs) in an electrical capacitor manufacturing plant in Indiana: an update. Environ Health Perspect 114(1): 18-23, 2006.

23 Mallin K, McCann K, D’Aloisio A, Freels S, Piorkowski J, Dimos J and Persky V: Cohort mortality study of capacitor manufacturing workers, 1944-2000. J Occup Environ Med 46(6): 565-576, 2004.

24 Hardell L, Bavel BM and Lindstrom G: Higher concentrations of specific polychlorinated biphenyl congeners in adipose tissue from non-Hodgkin's lymphoma patients compared with controls without a malignant disease. Int J Oncol 9(4): 603-608, 1996.

25 De Roos AJ, Hartge P, Lubin JH, Colt JS, Davis S, Cerhan JR, Severson RK, Cozen W, Patterson DG Jr., Needham LL and Rothman N: Persistent organochlorine chemicals in plasma and risk of non-Hodgkin's lymphoma. Cancer Res 65(23): 1121411226, 2005.

26 Engel LS, Laden F, Andersen A, Strickland PT, Blair A, Needham LL, Barr DB, Wolff MS, Helzlsouer K, Hunter DJ, Lan Q, Cantor KP, Comstock GW, Brock JW, Bush D, Hoover $\mathrm{RN}$ and Rothman N: Polychlorinated biphenyl levels in peripheral blood and non-Hodgkin's lymphoma: a report from three cohorts. Cancer Res 67(11): 5545-5552, 2007.

27 Ruder AM, Hein MJ, Hopf NB, and Waters MA: Mortality among 24,865 workers exposed to polychlorinated biphenyls (PCBs) in three electrical capacitor manufacturing plants: a tenyear update. Int J Hyg Environ Health 217(2-3): 176-187, 2014.

28 Mayes BA, McConnell EE, Neal BH, Brunner MJ, Hamilton SB, Sullivan TM, Peters AC, Ryan MJ, Toft JD, Singer AW, Brown JF Jr., Menton RG and Moore JA. Comparative carcinogenicity in Sprague-Dawley rats of the polychlorinated biphenyl mixtures Aroclors 1016, 1242, 1254, and 1260. Toxicolo Sci 41(1): 62-76, 1998.

29 ATSDR 2011. Addendum to toxicological profile for polychlorinated biphenyls (PCBs). Public health statement. Agency for Toxic Substances and Disease Registry. Atlanta, GA: 
U.S. Department of Health and Human Services, Public Health Service. 2011. (http://www.atsdr.cdc.gov/toxprofiles/ pcbs_ addendum.pdf).

30 CDC 2015. Centers for disease control and prevention (CDC): fourth national report on human exposure to environmental chemicals. Updated Tables February 2015. (http://www.cdc.gov/ exposurereport).

31 Ferriby LL, Knutsen JS, Harris M, Unice KM, Scott P, Nony P, Haws LC and Paustenbach D: Evaluation of PCDD/F and dioxinlike PCB serum concentration data from the 2001-2002 National Health and Nutrition Examination Survey of the United States population. J Expo Sci Environ Epidemiol 17: 358-371, 2007.

32 Michalik L, Auwerx J, Berger JP, Chatterjee VK, Glass CK Gonzalez FJ, Grimaldi PA, Kadowaki T, Lazar MA, O'Rahilly S, Palmer CN, Plutzky J, Reddy JK, Spiegelman BM, Staels B and Wahli W: International Union of Pharmacology. LXI. Peroxisome proliferator-activated receptors. Pharmacol Rev 58: 726-741, 2006.

33 Bookout AL, Jeong Y, Downes M, Yu RT, Evans RM and Mangelsdorf DJ: Anatomical profiling of nuclear receptor expression reveals a hierarchical transcriptional network. Cell 126: 789-799, 2006.

34 Guo D, Sarkar J, Ahmed MR, Viswakarma N, Jia Y, Yu S, Sambasiva Rao M, Reddy JK: Peroxisome proliferator-activated receptor (PPAR)-binding protein (PBP) but not PPAR-interacting protein (PRIP) is required for nuclear translocation of constitutive androstane receptor in mouse liver. Biochem Biophys Res Commun 347: 485-495, 2006.

35 Gonzalez FJ and Shah YM: PPARalpha: mechanism of species differences and hepatocarcinogenesis of peroxisome proliferators. Toxicology 246: 2-8, 2008.

36 Pyper SR, Viswakarma N, Yu S and Reddy JK: PPARalpha: energy combustion, hypolipidemia, inflammation and cancer. Nucl Recept Signal 8: e002, 2010.

37 Dong C, Zhou H, Shen C, Yu LG, Ding Y, Zhang YH and Guo ZR : Role of peroxisome proliferator-activated receptors gene polymorphisms in type 2 diabetes and metabolic syndrome. World J Diabetes 6: 654-661, 2015.

38 Montanez JE, Peters JM, Correll JB, Gonzalez FJ and Patterson AD: Metabolomics: an essential tool to understand the function of peroxisome proliferator-activated receptor alpha. Toxicol Pathol 41: 410-418, 2013.

39 Zarzuelo MJ, Jimenez R, Galindo P, Sanchez M, Nieto A, Romero M, Quintela AM, López-Sepúlveda R, Gómez-Guzmán M, Bailón E, Rodríguez-Gómez I, Zarzuelo A, Gálvez J, Tamargo J, Pérez-Vizcaíno F and Duarte J: Antihypertensive effects of peroxisome proliferator-activated receptor-beta activation in spontaneously hypertensive rats. Hypertension 58: 733-743, 2011.

40 Burris TP, Busby SA and Griffin PR: Targeting orphan nuclear receptors for treatment of metabolic diseases and autoimmunity. Chem Biol 19: 51-59, 2012.

41 Lambe KG and Tugwood JD: A human peroxisome-proliferatoractivated receptor-gamma is activated by inducers of adipogenesis, including thiazolidinedione drugs. Eur J Biochem 239: 1-7, 1996.

42 Tontonoz P and Spiegelman BM: Fat and beyond: the diverse biology of PPARgamma. Annu Rev Biochem 77: 289-312, 2008.

43 Rogue A, Spire C, Brun M, Claude N and Guillouzo A: Gene Expression Changes Induced by PPAR Gamma Agonists in Animal and Human Liver. PPAR Res 2010: 325183, 2010.
44 Sheikh IA: Stereoselectivity and the potential endocrine disrupting activity of di-(2-ethylhexyl)phthalate (DEHP) against human progesterone receptor: a computational perspective. J Appl Toxicol 36(5):741-747, 2016.

45 Nabuurs SB, Wagen er M and de Vlieg J: A flexible approach to induced fit docking. J Med Chem 50: 6507-6518, 2007.

46 Li F, Li X, Liu X, Zhang L, You L, Zhao J and Wu H: Docking and 3D-QSAR studies on the Ah receptor binding affinities of polychlorinated biphenyls (PCBs), dibenzo-p-dioxins (PCDDs) and dibenzofurans (PCDFs). Environ Toxicol Pharmacol 32(3): 478-485, 2011.

47 Yuan $\mathrm{J}, \mathrm{Pu}$ Y and Yin L: Prediction of binding affinities of PCDDs, PCDFs and PCBs using docking-based Comparative Molecular Similarity Indices Analysis. Environ Toxicol Pharmacol 38(1): 1-7, 2014.

48 Wahlang B, Falkner KC, Clair HB, Al-Eryani L, Prough RA, States JC, Coslo DM, Omiecinski CJ and Cave MC: Human receptor activation by aroclor 1260 , a polychlorinated biphenyl mixture. Toxicol Sci 140(2): 283-297, 2014.

49 De S, Pramanik SK, Williams AL and Dutta SK: Toxicity of polychlorobiphenyls and its bioremediation. Int J Hum Genet 4: 281-290, 2004.

50 Ramadass $\mathrm{P}$, Meerarani P, Toborek M, Robertson LW and Hennig B: Dietary flavonoids modulate PCB-induced oxidative stress, CYP1A1 induction, and AhR-DNA binding activity in vascular endothelial cells. Toxicol Sci 76: 212-219, 2003.

51 Arzuaga X, Reiterer G, Majkova Z, Kilgore MW, Toborek M and Hennig B: PPARalpha ligands reduce PCB-induced endothelial activation: possible interactions in inflammation and atherosclerosis. Cardiovasc Toxicol 7(4): 264-272, 2007.

52 Robertson LW, Berberian I, Borges T, Chen LC, Chow CK, Glauert HP, Filser JG and Thomsa H: Supression of peroxisomal enzyme activities and cytochrome P4504A isozyme expression by congeneric polybrominated and polychlorinated biphenyls. PPAR Res 15481, 2007, 2007.

53 Arsenescu V, Arsenescu RI, King V, Swanson H and Cassis LA: Polychlorinated biphenyl-77 induces adipocyte differentiation and proinflammatory adipokines and promotes obesity and atherosclerosis. Environ Health Perspect 116: 761-768, 2008.

54 Tremoen NH, Fowler PA, Ropstad E, Verhaegen S and Krogenæs A: Exposure to the three structurally different PCB congeners (PCB 118, 153, and 126) results in decreased protein expression and altered steroidogenesis in the human adrenocortical carcinoma cell line H295R. J Toxicol Environ Health A 77: 516-534, 2014.

55 Chu I, Villeneuve DC, Yagminas A, Lecavalier P, Håkansson H, Ahlborg UG, Valli VE, Kennedy SW, Bergman A, Seegal RF and Feely M. Toxicity of PCB 77 (3,3',4,4'-tetrachlorobiphenyl) and PCB $118\left(2,3^{\prime}, 4,4^{\prime}\right.$ '5-pentachlorobiphenyl) in the rat following subchronic dietary exposure. Fundam Appl Toxicol 26(2): 282-292, 1995.

56 NTP 2010: NTP technical report on the toxicology and carcinogenesis studies of 2,3',4,4',5-Pentachlorobipheny (PCB 118) (CAS No. 31508-00-6) in female Harlan Sprague-Dawley Rats (Gavage Studies). National Institutes of Health, US Department of Health and Human Services, NTP TR 559, NIH Publication no 115900. (http://ntp.niehs.nih.gov/ntp/htdocs/ lt_rpts/tr559.pdf).

Received May 9, 2016

Revised June 8, 2016

Accepted June 9, 2016 